\title{
Efficacy of Early Rehabilitation After Surgical Repair of Acute Aneurysmal Subarachnoid Hemorrhage: Outcomes After Verticalization on Days 2-5 Versus Day 12 Post-Bleeding
}

\author{
Andjela MILOVANOVIC ${ }^{1,2}$, Danica GRUJICIC ${ }^{2,3}$, Vojislav BOGOSAVLJEVIC ${ }^{2,3}$, Milos JOKOVIC ${ }^{2,3}$, \\ Natasa MUJOVIC ${ }^{1,2}$, Ivana Petronic MARKOVIC 2,4 \\ ${ }^{1}$ Clinical Centre of Serbia, Physical Medicine and Rehabilitation Clinic, Belgrade, Serbia \\ ${ }^{2}$ University of Belgrade, School of Medicine, Belgrade, Serbia \\ ${ }^{3}$ Clinical Centre of Serbia, Neurosurgery Clinic, Belgrade, Serbia \\ ${ }^{4}$ University Children's Hospital, Department of Physical Medicine and Rehabilitation, Belgrade, Serbia
}

\section{ABSTRACT}

AIM: To develop a specific rehabilitation protocol for patients who have undergone surgical repair of acute aneurysmal subarachnoid hemorrhage $(\mathrm{aSAH})$, and to determine the time at which verticalization should be initiated after aSAH.

MATERIAL and METHODS: Sixty-five patients who underwent acute-term surgery for aSAH and early rehabilitation were evaluated in groups: Group $1(n=34)$ started verticalization on days $2-5$ post-bleeding whereas Group 2 ( $n=31)$ started verticalization approximately day 12 post-bleeding. All patients were monitored for early complications, vasospasm and ischemia. Assessments of motor status, depression and anxiety (using Zung scales), and cognitive status (using the Mini-Mental State Examination (MMSE)) were conducted at discharge and at 1 and 3 months post-surgery.

RESULTS: At discharge, Group 1 had a significantly higher proportion of patients with ischemia than Group 2 ( $p=0.004$ ). Group 1 had a higher proportion of patients with hemiparesis than Group 2 three months post-surgery $(p=0.015)$. Group 1 patients scored significantly higher on the Zung depression scale than Group 2 patients at 1 month $(p=0.005)$ and 3 months post-surgery ( $p=0.001$; the same applies to the Zung anxiety scale ( $p=0.006$ and $p=0.000$, respectively). Group 2 patients scored significantly higher on the MMSE than those in Group 1 at discharge $(p=0.040)$ and 1 month post-surgery $(p=0.025)$.

CONCLUSION: Early verticalization had no effect with respect to preventing early postoperative complications in this patient group. Once a patient has undergone acute surgical repair of aSAH, it is safe and preferred that rehabilitation be initiated immediately postsurgery. However, verticalization should not start prior to day 12 post-bleeding.

KEYWORDS: Aneurysm, Post-bleeding, Early rehabilitation, Verticalization

ABBREVIATIONS: aSAH: Aneurysmal Subarachnoid Hemorrhage, MMSE: Mini-Mental State Examination, SAH: Subarachnoid Hemorrhage, SAS: Self-rating Anxiety Scale, SDS: Self-rating Depression Scale. 


\section{- INTRODUCTION}

A neurysmal subarachnoid hemorrhage (aSAH) is a lifethreatening condition that accounts for approximately $3 \%$ to $5 \%$ of all strokes, with half of affected patients younger than 55 years $(1,23)$. This pathology is responsible for up to $10 \%$ of all strokes that occur between ages 40 and 50 years, which is the most productive working period $(3,4,21)$. Subarachnoid hemorrhage $(\mathrm{SAH})$ is a frequently devastating condition that accounts for $5 \%$ of all strokes and affects as many as 30,000 North Americans each year $(8,14)$.

Many risk factors for aSAH have been identified. Cocainerelated aSAH has been documented in younger patients (17), and several risk factors are associated with increased likelihood of multiple aneurysms (e.g., smoking, hypertension, post-menopausal state, family history of cerebrovascular disease) $(5,12,20)$. Even though case fatality rates remain high, many factors are associated with better survival for patients with aSAH $(16,22)$. First among these is neurointensive care that can reduce secondary brain damage and prevent other neurologic injuries (1). Aneurysmal rebleeding, hydrocephalus, cerebral vasospasm and seizures are the most severe secondary complications. Pneumonia, electrolyte abnormalities, meningitis, and thrombosis are common medical complications (1). Such issues contribute to the burden of care in the acute phase. Long-term problems in survivors of aSAH include physical, emotional and cognitive difficulties, all of which can limit the patient's physical activity and participation in social activities and work $(9,18)$.

Re-bleeding is an important cause of death and disability in patients with aSAH. It has been shown that without surgery or anti-fibrinolytic treatment approximately $30 \%$ of these patients develop re-bleeding within 1 month of the initial hemorrhage (15), and approximately $50 \%$ of those patients die directly because of the re-bleeding (10). Consequently, occlusion of the aneurysm should be considered a priority (23).

Early rehabilitation for patients with $\mathrm{aSAH}$ should include early therapeutic exercise, a 45-degree pillow, respiratory rehabilitation, and gradual, controlled verticalization. At present, there is no standardized method for measuring neurological or psychological deficits in patients with aSAH, and it is not yet clear precisely when it is best to initiate verticalization post-surgery.

The aim of this study was to develop a specific rehabilitation protocol for this patient group and to determine the time at which verticalization should be initiated after aSAH. The study had four objectives: i) assess whether early verticalization of aSAH helps prevent early postoperative complications; ii) assess whether early verticalization after aSAH is related to occurrence of vasospasm; iii) assess for a relationship between vasospasm and brain ischemia among patients who undergo early rehabilitation with verticalization initiated on days 2-5 post-bleeding versus day 12 post-bleeding, and iv) compare occurrence of motor deficits among patients in these groups. Findings for depression, anxiety, and cognitive recovery were also compared between the groups.

\section{MATERIAL and METHODS}

The study was a prospective, randomized, clinical trial. All subjects were patients in the Neurosurgery Clinic of the Clinical Center of Serbia between June 2013 and June 2015. The investigation was approved by the Ethics Committee of the School of Medicine, University of Belgrade. Patients were informed about the study as required by this committee, and 65 participants gave informed consent for enrollment. All underwent surgery in the acute term of aSAH (i.e., within the first 3 days after aneurysm rupture; clinical status classified as grade I, II or III on the Hunt and Hess scale (11) regardless of aneurysm location). All underwent complete clinical examination (i.e., computed tomography (CT), lumbar puncture for cerebrospinal fluid analysis, angiography or CT-angiography) and any other clinical and specialized consultations required. The exact date of each patient's aSAH occurrence was recorded based on the medical history.

Following surgery for aSAH, each participant was randomly assigned to one of two groups that underwent the same early rehabilitation but initiated verticalization at different times: Group $1(n=34)$ started verticalization (to the level matching their specific neurological findings) on days 2-5 postbleeding (i.e., 2 days post-surgery); Group $2(n=31)$ started verticalization on day 12 post-bleeding (i.e., between 9 and 12 days post-surgery).

All patients were carefully monitored and subjected to a complete medical examination daily during the hospitalization period (i.e., first 15 days post-surgery). All relevant documents (e.g., operative reports, anesthesia records, and medication administration records) were analyzed and patient status was noted daily. Evaluations included assessing whether the patient was awake, could communicate adequately, or was experiencing headaches. Early postoperative complications (e.g., pneumonia, atelectasis, embolism, edema, deep venous thrombosis, fever, meningitis, urinary infections, wound dehiscence, and diarrhea) were carefully documented throughout the hospitalization period. Limb mobility was tested and complete laboratory results and other test results were evaluated, such as chest radiography, CT scans, and cerebrospinal fluid analysis. When all results were within normal limits and a patient exhibited no clinical signs of vasospasm, the early rehabilitation algorithm was initiated.

Both groups received the same early rehabilitation. The program involved bed exercises initially, followed by respiratory rehabilitation and finally a 45-degree pillow. As noted, verticalization was started early ( 2 to 5 days post-bleeding) in Group 1, and later (approximately 12 days post-bleeding) in Group 2. If a patient developed clinical signs of vasospasm, the rehabilitation plan was reduced in consultation with a neurosurgeon, and verticalization was halted until the patient was stabilized. Similarly, if a patient developed ischemia (confirmed by CT), he/she was stabilized before rehabilitation was continued.

Considering the difficulties that patients in both groups might encounter, even minor signs of complications were investigated with CT to assess for potential development of 
hydrocephalus and ischemia. On the day of discharge, each patient's neurological status and limb mobility were assessed. Each individual was also evaluated using established tests for depression, and anxiety and cognitive status (see details below).

Follow-up examinations were performed at 1 and 3 months post-surgery. At each check, limb mobility and overall extent of mobility were evaluated and the tests for depression, anxiety, and cognitive status were re-administered.

\section{Tests and Scales}

Depression: The scale for self-rating of depression (Selfrating Depression Scale, or SDS) was established by Zung in 1965 (25). This instrument assesses patients for basic characteristics of depression: affect disturbance (e.g., bad mood, sadness, crying), physiological disturbance (e.g., awaking during the night, tachycardia, arrhythmia, poor appetite), psychomotor disturbance (e.g., slow movement in time and space, anxiety, muscle spasms), and psychic disturbance (e.g., indecision, confusion, discontent with life, suicidal thoughts). It contains 20 questions/statements that require answers based on a four-tier scale: never or very rarely, sometimes, often, predominantly or always. The statements are positively and negatively oriented, and the total score can range from 20 to 80 . According to extensive literature on the use of the SDS (25), patients with mild depression score 4049 , those with moderate depression score $50-59$, and those with severe depression score 60 or higher.

Anxiety: The Zung scale for self-rating anxiety (Self-rating Anxiety Scale, or SAS) was established in 1971 (24). It contains 20 positive or negative statements that evaluate symptoms of affective, physiological, psychomotor and psychic disturbances. The scale measures the patient's disturbances in the week prior to the test, with answers given on a four-tier scale: never or very rarely, sometimes, often, and predominantly or always. The range of scores is same as with the SDS (total score 20-80). Individuals with mild anxiety score $40-49$, those with moderate anxiety score 50-59, and those with severe anxiety score 60 or higher.

Cognitive Status: Cognitive damage (i.e., altered orientation in time and space, memory deficits) was measured using the Mini-Mental State Examination (MMSE), a 30-question screening test that identifies possible cognitive difficulties. Any positive answer scores one point. The maximum score is 30 and a score below 24 is considered abnormal (7). The MMSE is a rapid test and does not cause patient fatigue.

\section{Statistical Methods}

Data were analyzed using descriptive statistics (i.e., mean and median, standard deviation, coefficient of variation, standard error, minimum and maximum). Data for each study variable were tested for normal distribution using the KolmogorovSmirnov test. Variables that satisfied this criterion were analyzed using parametric methods (i.e., Pearson's chi-square test, Student's t-test). The remaining variables were analyzed using nonparametric methods (i.e., Mann-Whitney $U$ test). Associations between variables were assessed using single- and multi-parametric correlation and regression, as well as non-parametric correlation, depending on the distribution of data. Multiple logistic regression models were used to examine classifiers or predictor variables for two randomly generated groups. In addition, multiple linear regression models were used to examine outcome predictors. $\mathrm{P}$ values $<0.05$ were taken to indicate statistical significance.

\section{- RESULTS}

Table I lists patients' demographic data and their clinical status on the Hunt and Hess scale. Average patient age was 51.9 years (range, 25-71 years). Women comprised approximately two-thirds of each group ( $p=0.993)$. Comparisons revealed no significant differences between the groups with respect to frequency of clinical grades (I to III). There was also no statistical difference between the groups with respect to development of early postoperative complications (Table II).

Table III summarizes the group results for hemiplegia, hemiparesis, vasospasm, and ischemia. At the time of discharge, Group 1 had a higher proportion of patients with hemiplegia than Group 2 ( $21 \%$ vs. $3 \%$, respectively; $p=0.035)$. A difference was also noted at the 1-month follow-up exam ( $12 \%$ vs. $0 \%$, respectively; $p=0.050$ ), whereas there was no statistical difference at the 3 -month exam. There were no significant differences between the groups with respect to proportions of patients with hemiparesis at discharge. However, Group 1 had a higher proportion of patients with hemiparesis than Group 2 at the 1-month follow-up (50\% vs. $26 \%$, respectively; $\mathrm{p}=0.047)$ and at 3 months $(44 \%$ vs. $16 \%$, respectively; $p=0.015)$. Seventeen $(26.2 \%)$ of the 65 patients developed vasospasm at 8 to 11 days post-bleeding: 11 patients (32.4\%) in Group 1 and six (19.4\%) in Group 2. At the time of discharge, Group 1 had a significantly higher proportion of patients with ischemia than Group $2\left(X^{2}=8.370\right.$; $\mathrm{p}=0.004$ ).

Group 1 patients scored significantly higher on the Zung depression scale than those in Group 2 at 1 month $(91.2 \%$ vs. $51.6 \%$, respectively; $p=0.005$ ) and 3 months post-surgery $(85.3 \%$ vs. $48.4 \%$, respectively; $p=0.001)$; however, there was no statistical difference between the groups at discharge (Table IV).

Group 1 patients scored significantly higher on the Zung anxiety scale than those in Group 2 at 1 month $(76.4 \%$ vs. $32.2 \%$, respectively; $p=0.006$ ) and 3 months post-surgery ( $64.7 \%$ vs. $29 \%$, respectively; $p<0.001)$; however, there was no statistical difference between the groups at discharge (Table V).

Group 2 patients scored significantly higher on the MMSE than those in Group 1 at discharge (61.3\% vs. $41.2 \%$, respectively; $\mathrm{p}=0.040)$ and 1 month post-surgery $(83.9 \%$ vs. $64.7 \%$, respectively; $\mathrm{p}=0.025$ (Table VI).

\section{DISCUSSION}

The main finding of our study was that early verticalization did not have an effect on the prevention of early postoperative 
complications. Moreover, the study indicated that early verticalization could potentiate vasospasm, and we detected a correlation between vasospasm and the occurrence of ischemia.

Reportedly, no randomized control trial has yet provided evidence for how long it is necessary to remain in bed after
aSAH, and researchers worldwide have been invited to collaborate actively on resolving this issue (13). One advantage of our study was that it compared two homogenous, randomized groups of patients with aSAH.

Our results demonstrate a need to consider cognitive state when assessing a patient's functional status after aSAH. The

Table I: Patient Demographic Characteristics for the Two Study Groups

\begin{tabular}{|c|c|c|c|c|c|c|c|c|}
\hline & & & (early & 1 & (later & $\begin{array}{l}\text { Group } 2 \\
\text { verticalization) }\end{array}$ & \multicolumn{2}{|c|}{ Total } \\
\hline & & $\mathrm{n}$ & \multicolumn{2}{|c|}{34} & \multicolumn{2}{|r|}{31} & \multicolumn{2}{|c|}{65} \\
\hline & & $x$ & \multicolumn{2}{|c|}{51.76} & \multicolumn{2}{|r|}{51.94} & \multicolumn{2}{|c|}{51.85} \\
\hline \multirow{4}{*}{$\begin{array}{l}\text { Age } \\
\text { (years) } \\
p=0.943\end{array}$} & & SD & \multicolumn{2}{|c|}{10.75} & \multicolumn{2}{|r|}{8.22} & \multicolumn{2}{|c|}{9.56} \\
\hline & & Med & \multicolumn{2}{|c|}{53.5} & \multicolumn{2}{|r|}{53.0} & \multicolumn{2}{|c|}{53} \\
\hline & & Min & \multicolumn{2}{|c|}{25} & \multicolumn{2}{|r|}{37} & \multicolumn{2}{|c|}{25} \\
\hline & & Max & \multicolumn{2}{|c|}{71} & \multicolumn{2}{|r|}{65} & \multicolumn{2}{|c|}{71} \\
\hline \multirow{4}{*}{$\begin{array}{l}\text { Hunt and } \\
\text { Hess } \\
\text { Grade } \\
p=0.446\end{array}$} & Grade I & n (\%) & 3 & $(8.8)$ & 6 & $(19.4)$ & 9 & (13.8) \\
\hline & Grade II & n (\%) & 25 & (73.5) & 21 & $(67.7)$ & 46 & (70.8) \\
\hline & Grade III & n (\%) & 6 & $(17.6)$ & 4 & (12.9) & 10 & (15.4) \\
\hline & Total & n (\%) & 34 & $(52.3)$ & 31 & $(47.7)$ & 65 & $(100)$ \\
\hline \multirow{3}{*}{$\begin{array}{l}\text { Sex } \\
p=0.993\end{array}$} & Male & n (\%) & 11 & $(32.4)$ & 10 & $(32.3)$ & 21 & (32.3) \\
\hline & Female & n (\%) & 23 & $(67.6)$ & 21 & $(67.7)$ & 44 & (67.7) \\
\hline & Total & n (\%) & 34 & (52.3) & 31 & $(47.7)$ & 65 & (100) \\
\hline
\end{tabular}

$p$-values indicate the level of statistical significance.

Table II: Results for Occurrence of Early Postoperative Complications in Group 1 (Early Verticalization) and Group 2 (Later Verticalization)

\begin{tabular}{lcccc}
\hline & \multicolumn{2}{c}{ Group 1 (n=34) } & \multicolumn{2}{c}{ Group 2 (n=31) } \\
\cline { 2 - 5 } & $\mathbf{n}$ & $\mathbf{( \% )}$ & $\mathbf{n}$ & $\mathbf{( \% )}$ \\
\hline Pneumonia & 12 & $(35.3)$ & 7 & $(22.6)$ \\
\hline Atelectasis & 0 & $(0.0)$ & 0 & $(0.0)$ \\
\hline Embolism & 0 & $(0.0)$ & 0 & $(0.0)$ \\
\hline Deep-vein thrombosis & 0 & $(0.0)$ & 3 & $(9.7)$ \\
\hline Fever & 17 & $(50.0)$ & 10 & $(32.3)$ \\
\hline Meningitis & 11 & $(32.4)$ & 5 & $(16.1)$ \\
\hline Urinary infection & 2 & $(5.9)$ & 1 & $(3.2)$ \\
\hline Wound dehiscence & 6 & $(17.7)$ & 2 & $(6.5)$ \\
\hline Diarrhea & 1 & $(2.9)$ & 1 & $(3.2)$ \\
\hline Pulmonary edema & 1 & $(2.9)$ & 0 & $(0.0)$ \\
\hline Total number of patients with & 23 & $(67.6)$ & 14 & $(45.2)$ \\
early complications $p=0.067$ & & & & \\
\hline
\end{tabular}

p-value indicates the level of statistical significance. 
Table III: Results for Occurrence of Hemiplegia, Hemiparesis, Vasospasm and Ischemia in Group 1 (Early Verticalization) and Group 2 (Later Verticalization)

\begin{tabular}{|c|c|c|c|c|c|}
\hline & & \multicolumn{2}{|c|}{ Group $1(n=34)$} & \multicolumn{2}{|c|}{ Group $2(n=31)$} \\
\hline & & $\mathbf{n}$ & (\%) & $\mathrm{n}$ & (\%) \\
\hline \multirow{3}{*}{ Hemiplegia } & At discharge $\boldsymbol{p}=\mathbf{0 . 0 3 5}$ & 7 & (21) & 1 & (3) \\
\hline & After 1 month $p=0.050$ & 4 & (12) & 0 & $(0.0)$ \\
\hline & After 3 months $p=0.173$ & 2 & (6) & 0 & $(0.0)$ \\
\hline \multirow{3}{*}{ Hemiparesis } & At discharge $p=0.069$ & 15 & (44) & 7 & (23) \\
\hline & After 1 month $\boldsymbol{p}=\mathbf{0 . 0 4 7}$ & 17 & (50) & 8 & (26) \\
\hline & After 3 months $p=0.015$ & 15 & (44) & 5 & (16) \\
\hline \multirow{4}{*}{ Vasospasm } & 3-4 days post-bleeding & 5 & $(14.7)$ & 0 & $(0.0)$ \\
\hline & 5-7 days post-bleeding & 9 & $(26.5)$ & 1 & (3.2) \\
\hline & 8-11 days post-bleeding & 11 & $(32.4)$ & 6 & $(19.4)$ \\
\hline & 12 days post-bleeding & 0 & $(0.0)$ & 2 & $(6.5)$ \\
\hline \multicolumn{2}{|c|}{ Ischemia at Discharge $p=0.004$} & 22 & $(64.7)$ & 8 & (25.0) \\
\hline
\end{tabular}

$p$-values indicate the level of statistical significance. * the bold $p$-values values indicate a significant difference.

Table IV: Results for Depression According to the Zung Scale in Group 1 (Early Verticalization) and Group 2 (Later Verticalization)

\begin{tabular}{|c|c|c|c|c|c|c|c|c|c|c|c|c|}
\hline \multirow{3}{*}{ Depression } & \multicolumn{4}{|c|}{ At discharge $p=0.106$} & \multicolumn{4}{|c|}{ After 1 month $\mathrm{p}=0.005$} & \multicolumn{4}{|c|}{ After 3 months $p=0.001$} \\
\hline & \multicolumn{2}{|c|}{ Group $1(n=34)$} & \multicolumn{2}{|c|}{ Group $2(n=31)$} & \multicolumn{2}{|c|}{ Group $1(n=34)$} & \multicolumn{2}{|c|}{ Group $2(n=31)$} & \multicolumn{2}{|c|}{ Group $1(n=34)$} & \multicolumn{2}{|c|}{ Group $2(n=31)$} \\
\hline & $\mathbf{n}$ & $(\%)$ & $\mathbf{n}$ & (\%) & $\mathbf{n}$ & (\%) & $\mathbf{n}$ & (\%) & $\mathbf{n}$ & $(\%)$ & $\mathbf{n}$ & (\%) \\
\hline No signs & 7 & (20.6) & 16 & $(51.6)$ & 3 & (8.8) & 15 & $(48.4)$ & 5 & $(14.7)$ & 16 & $(51.6)$ \\
\hline Mild & 13 & $(38.2)$ & 5 & $(16.1)$ & 9 & $(26.5)$ & 6 & $(19.4)$ & 6 & (17.6) & 4 & (12.9) \\
\hline Moderate & 7 & $(20.6)$ & 6 & (19.4) & 10 & $(29.4)$ & 5 & $(16.1)$ & 12 & $(35.3)$ & 6 & (19.4) \\
\hline Severe & 7 & $(20.6)$ & 4 & (12.9) & 12 & (35.3) & 5 & $(16.1)$ & 11 & (32.4) & 5 & (16.1) \\
\hline Total & 34 & (100) & 31 & (100) & 34 & (100) & 31 & 100 & 34 & (100) & 31 & (100) \\
\hline
\end{tabular}

$p$-values indicate the level of statistical significance. * the bold p-values values indicate a significant difference.

Table V: Results for Anxiety according to the Zung Scale in Group 1 (Early Verticalization) and Group 2 (Later Verticalization)

\begin{tabular}{|c|c|c|c|c|c|c|c|c|c|c|c|c|}
\hline \multirow{3}{*}{ Depression } & \multicolumn{4}{|c|}{ At discharge $p=0.223$} & \multicolumn{4}{|c|}{ After 1 month $p=0.006$} & \multicolumn{4}{|c|}{ After 3 months $p<0.001$} \\
\hline & \multicolumn{2}{|c|}{ Group $1(n=34)$} & \multicolumn{2}{|c|}{ Group $2(n=31)$} & \multicolumn{2}{|c|}{ Group $1(n=34)$} & \multicolumn{2}{|c|}{ Group $2(n=31)$} & \multicolumn{2}{|c|}{ Group $1(n=34)$} & \multicolumn{2}{|c|}{ Group $2(n=31)$} \\
\hline & $\mathbf{n}$ & $(\%)$ & $\mathbf{n}$ & (\%) & $\mathbf{n}$ & (\%) & $\mathbf{n}$ & (\%) & $\mathbf{n}$ & (\%) & $\mathbf{n}$ & $(\%)$ \\
\hline No signs & 16 & $(47.1)$ & 20 & $(64.5)$ & 8 & $(23.6)$ & 21 & $(67.8)$ & 12 & (35.3) & 22 & (71.0) \\
\hline Mild & 9 & $(26.5)$ & 5 & $(16.1)$ & 13 & (38.2) & 5 & (16.1) & 8 & $(23.5)$ & 7 & (22.5) \\
\hline Moderate & 7 & $(20.6)$ & 4 & $(12.9)$ & 10 & $(29.4)$ & 4 & $(12.9)$ & 9 & $(26.5)$ & 2 & (6.5) \\
\hline Severe & 2 & (5.9) & 2 & (6.5) & 3 & (8.8) & 1 & (3.2) & 5 & $(14.7)$ & 0 & $(0.0)$ \\
\hline Total & 34 & (100) & 31 & (100) & 34 & (100) & 31 & (100) & 34 & (100) & 31 & (100) \\
\hline
\end{tabular}

$p$-values indicate the level of statistical significance. * the bold $p$-values values indicate a significant difference. 
Table VI: Results for Cognition according to the Mini-Mental State Examination (MMSE) in Group 1 (Early Verticalization) and Group 2 (Later Verticalization)

\begin{tabular}{|c|c|c|c|c|c|c|c|c|c|c|c|c|}
\hline \multirow{2}{*}{$\begin{array}{l}\text { Cognitive } \\
\text { problems }\end{array}$} & \multicolumn{4}{|c|}{ At discharge $p=0.040$} & \multicolumn{4}{|c|}{ After 1 month $p=0.025$} & \multicolumn{4}{|c|}{ After 3 months $p=0.073$} \\
\hline & $\mathbf{n}$ & (\%) & $\mathbf{n}$ & $(\%)$ & $\mathbf{n}$ & (\%) & $\mathbf{n}$ & $(\%)$ & $\mathbf{n}$ & $(\%)$ & $\mathbf{n}$ & (\%) \\
\hline Present & 20 & (58.8) & 12 & $(38.7)$ & 12 & (35.3) & 5 & $(16.1)$ & 6 & $(17.6)$ & 3 & $(9.7)$ \\
\hline Absent & 14 & $(41.2)$ & 19 & (61.3) & 22 & $(64.7)$ & 26 & (83.9) & 28 & (82.4) & 28 & (90.3) \\
\hline
\end{tabular}

$p$-values indicate the level of statistical significance. ${ }^{*}$ the bold $p$-values values indicate a significant difference.

findings also show that the appropriate approach to patient assessment is to apply motor recovery testing in conjunction with the MMSE and the Zung scales for depression and anxiety. It was sensible to include all patients from both groups in the early rehabilitation program, and to assess their functional status as soon as possible to determine who would require further physical rehabilitation and who suffered from depression, anxiety, or cognitive deficits.

The purpose of early rehabilitation for aSAH patients is to prevent potential postoperative complications and promote functional recovery. Our finding of no statistical difference between the early- and later-verticalization groups with respect to development of early postoperative complications does not support the strategy of early verticalization since early verticalization did not result in more effective prevention of such complications.

Our findings also indicate that verticalization should not be initiated during the vasospasm period. The early-verticalization group commenced verticalization during the period that coincides with the highest risk of vasospasm. The mechanisms of vasospasm and the factors that determine its occurrence and intensity are not fully understood, but it is possible that physical activation and verticalization during this period increase the likelihood of vasospasm occurring. One of the most challenging fields in rehabilitation medicine is early rehabilitation after aSAH precisely because it is presumed that increased physical activity may have an adverse effect on intracranial pressure and/or arterial blood pressure and result in a reduction of the cerebral perfusion pressure (13). Secondary brain damage may be triggered by these processes. A major concern in such cases is the aggravation of cerebral vasospasm and the occurrence of a delayed ischemic neurological deficit (13). In addition, verticalization induces orthostatic hypotension.

Furthermore, since vasospasm results in ischemia, it was not surprising that our early-verticalization group (the group with higher proportion of patients with vasospasm) also had a greater number of patients with ischemia at discharge. Our results point to the need to minimize factors that might increase the likelihood of or potentiate vasospasm in this patient group.
At discharge and 1 month post-surgery, we also observed higher proportions of patients with hemiplegia in the earlyverticalization group. As well, patients in the later-verticalization group made better recoveries from hemiplegia and hemiparesis. Regarding occurrence of hemiparesis, there was no significant difference between the two groups at discharge; however, at the 1- and 3-month follow-up examinations the numbers increased in the early-verticalization group as some of these patients recovered from hemiplegia.

Multiple studies have examined incidence of neurological deficits (motor deficiencies and physical changes) and changes in quality of life for aSAH patients after vasospasm, and this research has revealed high proportions of cases in which vasospasm contributed to the onset of such deficits $(2,6,19)$. The deficits included irritability, depression, anxiety, decreased memory performance and reduced speed of information processing, as well as substantial reductions in quality of life. Our results were in accord with these findings. It is also noteworthy that depression, anxiety, and cognitive disorders can be caused or aggravated not only by the factors mentioned above, but also by a patient's low socioeconomic status, standard of living, and individual characteristics prior to aSAH.

\section{CONCLUSION}

Mental health of aSAH patients is as important as their physical health; therefore, it is very important to adopt a multidisciplinary approach when treating these patients. Once an individual has undergone acute surgical repair of aSAH, it is safe and preferred that rehabilitation be initiated immediately post-surgery. The program should involve bed exercises and verticalization should not start prior to day 12 post-bleeding.

\section{REFERENCES}

1. Bederson JB, Connolly ES Jr, Batjer HH, Dacey RG, Dion JE, Diringer MN, Duldner JE Jr, Harbaugh RE, Patel AB, Rosenwasser $\mathrm{RH}$ : Guidelines for the management of aneurysmal subarachnoid hemorrhage: A statement for healthcare professionals from a special writing group of the stroke council, American Heart Association. Stroke 40: 9941025, 2009 
2. Cedzich C, Roth A: Neurological and psychosocial outcome after subarachnoid haemorrhage, and the Hunt and Hess scale as a predictor of clinical outcome. Zentralbl Neurochir 66: 112-118, 2005

3. Clinchot MD, Bogner JA, Kaplan PE: Cerebral aneurysms: Analysis of rehabilitation outcomes. Arch Phys Med Rehabil 78: 346-349, 1997

4. Dombovy ML, Drew-Cates J, Serdans R: Recovery and rehabilitation following subarachnoid haemorrhage. Part I: outcome after inpatient rehabilitation. Brain Inj 12: 443-454, 1998

5. Ellamushi HE, Grieve JP, Jager HR, Kitchen ND: Risk factors for the formation of multiple intracranial aneurysms. J Neurosurg 94: 728-732, 2001

6. Fertl E, Killer M, Eder H, Linzmayer L, Richling B, Auff E: Long-term functional effects of aneurysmal subarachnoid haemorrhage with special emphasis on the patient's view. Acta Neurochir 141: 571-577, 1999

7. Folstein MF, Folstein ME, McHugh PR: Mini-mental state: A practical method for grading the cognitive state of patients for the clinician. J Psychiatr Res 12(3):189-198, 1975

8. Graf CJ, Nibbelink DW: Cooperative Study of intracranial aneurysms and subarachnoid hemorrhage: Report on a randomized treatment study. 3. Intracranial surgery. Stroke 5: 557-601, 1974

9. Haug T, Sorteberg A, Sorteberg W, Lindegaard KF, Lundar T, Finset $A$ : Cognitive outcome after aneurysmal subarachnoid hemorrhage: Time course of recovery and relationship to clinical, radiological, and management parameters. Neurosurgery 60: 649-656, 2007

10. Hijdra A, Vermeulen M, van Gijn J, van Crevel H: Re-rupture of intracranial aneurysms: A clinicoanatomic study. J Neurosurg 67: 29-33, 1987

11. Hunt WE, Hess RM: Surgical risk as related to time of intervention in the repair of intracranial aneurysms. J Neurosurg 28: 14-20, 1968

12. Juvela S: Risk factors for multiple intracranial aneurysms. Stroke 31: 392-397, 2000

13. Karic T, Sorteberg A, Haug Nordenmark T, Becker F, Roe C: Early rehabilitation in patients with acute aneurysmal subarachnoid hemorrhage. Disabil Rehabil 37:1446-1454, 2015
14. King JT Jr: Epidemiology of aneurysmal subarachnoid hemorrhage. Neuroimaging Clin N Am 7: 659-668, 1997

15. Locksley HB: Natural history of subarachnoid hemorrhage, intracranial aneurysms and arteriovenous malformations. J Neurosurg 25: 321-368, 1966

16. Lovelock CE, Rinkel GJ, Rothwell PM: Time trends in outcome of subarachnoid hemorrhage: Population-based study and systematic review. Neurology 74: 1494-1501, 2010

17. Nanda A, Vannemreddy PS, Polin RS, Willis BK: Intracranial aneurysms and cocaine abuse: Analysis of prognostic indicators. Neurosurgery 46: 1063-1067, 2000

18. Passier PE, Visser-Meily JM, Rinkel GJ, Lindeman E, Post MW: Life satisfaction and return to work after aneurysmal subarachnoid hemorrhage. J Stroke Cerebrovasc Dis 20: 324-329, 2011

19. Pluta RM, Hansen-Schwartz J, Dreier J, Vajkoczy $P$, Macdonald RL, Nishizawa S, Kasuya H, Wellman G, Keller E, Zauner A, Dorsch N, Clark J, Ono S, Kiris T, Leroux P, Zhang $\mathrm{JH}$ : Cerebral vasospasm following subarachnoid hemorrhage: Time for world of thought. Neurol Res 31: 151-158, 2009

20. Qureshi Al, Suarez JI, Parekh PD, Sung G, Geocadin R, Bhardwaj A, Tamargo RJ, Ulatowski JA: Risk factors for multiple intracranial aneurysms. Neurosurgery 43:22-26, 1998

21. Säveland $H$, Brandt $L$ : Which are the major determinants for outcome in aneurysmal subarachnoid hemorrhage? A prospective total management study from a strictly unselected series. Acta Neurol Scand 90: 245-250, 1994

22. Sveinsson $\mathrm{OA}$, Olafsson $\mathrm{IH}$, Kjartansson $\mathrm{O}$, Valdimarsson EM: Spontaneous subarachnoid haemorrhage-review. Laeknabladid 97: 355-362, 2011

23. van Gijn J, Kerr RS, Rinkel GJ: Subarachnoid haemorrhage. Lancet 369: 306-318, 2007

24. Zung WW: A rating instrument for anxiety disorders. Psychosomatics 12: 371-379, 1971

25. Zung WW: A self- rating depression scale. Arch Gen Psychiatry 12: 63-70, 1965 